\title{
Differential Cost-Sharing Undermines Treatment Adherence to Combination Therapy: Evidence from Diabetes Treatment
}

\author{
David R. Nelson · Pamela Heaton · Ana Hincapie · Shirin Ghodke • \\ Jieling Chen
}

Received: May 3, 2021 / Accepted: June 10, 2021 / Published online: July 1, 2021

(C) The Author(s) 2021

\section{ABSTRACT}

Introduction: The objective of this study was to measure the influence of differences in out-ofpocket (OOP) costs for type 2 diabetes (T2D) medications on within-patient adherence behavior towards combination drug therapy regimens.

Methods: This was an observational, retrospective, paired sample study in patients with T2D using longitudinal pharmacy data from the 2009-2014 Medical Expenditure Panel Survey (MEPS) augmented with socio-demographic factors. We took a within-patient approach to minimize confounding effects by including patients who maintained the same number of diabetes drug classes over 2 years of MEPS. For each patient, we selected the most and least costly drug classes in the second year and examined their

Supplementary Information The online version contains supplementary material available at https:// doi.org/10.1007/s13300-021-01098-8.

D. R. Nelson $(\bowtie) \cdot J$. Chen

Lilly Corporate Center, Eli Lilly and Company,

Indianapolis, IN 46285, USA

e-mail: nelson_david_r@lilly.com

P. Heaton · A. Hincapie

James L. Winkle College of Pharmacy, University of Cincinnati, Cincinnati, OH, USA

S. Ghodke

Eli Lilly Services India Private Limited, Bengaluru,

Karnataka, India corresponding adherence behavior measured by medication possession ratio. The primary hypothesis tested the significance of the correlation between magnitude of the OOP cost difference and behavioral response in adherence.

Results: Analysis included 1189 patients representing over 4.2 million US residents with T2D. A significant negative correlation $(p<0.001)$ was observed between the differences of OOP costs and adherence to the most and least costly medications compared within patients. Reduction in adherence to the most costly medication was generally observed when the difference in OOP costs was greater than \$33/month. A greater variability in adherence was observed when the cost difference exceeded $\$ 2.39 /$ month as compared to other cost difference ranges $(p<0.001)$, indicative of choices being made.

Conclusions: As OOP costs increased, adherence variability increased initially until a cost threshold, beyond which the adherence to the more costly medication decreased. In addition to OOP cost, adherence was also influenced by type of medication and self-perception of health. Given the complex correlation between OOP costs and adherence to medication, we suggest a careful approach to cost-sharing in the current insurance drug design and relevant insurance policies.

Keywords: Adherence; Healthcare out-ofpocket costs; Diabetes combination therapy; Insurance design; Medical Expenditure Panel Survey (MEPS) 


\section{Key Summary Points}

Why carry out this study?

Multiple therapy becomes increasingly important for patients with type 2 diabetes (T2D) and current insurance designs may make some patients less adherent to medications. Adherence to diabetes medications is low when out-ofpocket (OOP) costs and insurance copayments are high. A 10\% increase in patient cost-sharing may decrease adherence by $5.4-6.2 \%$ depending on medication class.

Since out-of-pocket (OOP) costs for the individual components of combination therapy may differ, it is not known whether OOP cost differences impact adherence to combination therapy. The study examined the correlation between magnitude of the OOP cost difference and behavioral response in adherence to combination therapy.

\section{What was learned from the study?}

Using the within-patient approach for analysis, we were able to minimize the impact of confounding factors on the relationship between OOP costs and adherence behavior, which is a common issue in cross-sectional studies.

Within the cohort, patients behave differently to cost differences to the medications they are taking. As OOP costs increased, the effect on adherence initially was more variable until a cost threshold beyond which the adherence to the more costly medication decreased.

Given the complex correlation between OOP costs and adherence to medication, we suggest a careful approach to costsharing in the current insurance drug design and relevant insurance policies.

\section{DIGITAL FEATURES}

This article is published with digital features, including a summary slide, to facilitate understanding of the article. To view digital features for this article go to https://doi.org/10.6084/ m9.figshare.14749503.

\section{INTRODUCTION}

As a chronic metabolic disorder, diabetes poses a significant economic burden on the United States (US) healthcare system. A portion of the high cost of diabetes medical expenditure was considered to be contributed by overconsumption of healthcare resources induced by the availability of health insurance, and thus has been viewed as an economic inefficiency that would lead to "welfare loss," or decreased economic well-being $[1,2]$. To control the cost, patients with diabetes are offered cost-sharing schemes in the form of deductibles, co-insurance, or co-payments [3]. However, the greater adoption of consumer-directed or high-deductible health plans has led to an unprecedented increase in initial out-of-pocket (OOP) costs $[4,5]$. Cost-sharing schemes may be effective in reducing the economic inefficiency if patients are able to rationally weigh in the benefits and risks of the healthcare resources available to them, as is assumed by the traditional economic theory that was based on insurance-induced moral hazard theory $[6,7]$.

Breaking away from this traditional theory, some economists $[8,9]$ argue that imposing high cost-sharing may negatively impact patient health. Patients with serious illnesses may not have sufficient experience and knowledge to make appropriate medical choices and may opt for less effective therapy if essential care is not affordable. High cost-sharing could render healthcare unaffordable for people with low incomes. The Affordable Care Act (2010) offered free preventive services and provided insurance coverage to some people from the lower income group, thereby reducing their OOP spending. However, a majority of patients continue to experience a high burden of OOP and insurance premium expense [10]. Higher 
cost-sharing may lead to delayed drug initiation and reduced adherence to medication, which contributes to poor health outcomes and ultimately higher healthcare resource utilization, defeating the purpose of cost-sharing [11-14].

As T2D is a progressive disease, maintenance of glycemic control with combination therapy often becomes necessary over time [15]. Combination therapy during the early treatment of T2D allows faster attainment of glycemic goals compared with sequential addition of medications that may result in primary and secondary failure [16-18]. In the tiered cost-sharing insurance design, patients often face different OOP costs for each of the medications within their combination therapy regimen. The difference in the OOP costs is likely to be even larger for those in high-deductible or consumer-driven insurance plans.

For patients with type 2 diabetes (T2D), poor adherence to therapy is particularly detrimental with increased difficulty in managing its downstream complications [19-21]. As adherence to medication may be significantly influenced by OOP costs [22-24], the association between adherence and OOP costs in patients with T2D has been widely studied but with several methodologic variations [25]. The results vary greatly across studies, ranging from no association to a significant inverse relationship [23]. A challenging aspect of studying OOP costs and adherence is potential confounding factors, which make it difficult to estimate the specific contribution of their relationship to adherence.

In this study, we analyzed data from patients utilizing combination therapy for T2D and examined the correlation between OOP costs and medication adherence. We study whether OOP cost differences impact adherence to their combination therapy. Rather than trying to capture the large number of measured and unmeasured interpatient confounding variables (much less integrate their collinearity), or to identify and successfully implement instrumental variables, our study design simplified the analysis in a novel way. By using paired samples with the concept of individuals serving as their own controls rather than a cross-sectional approach, we controlled any causal and confounding factors and reduced interpatient variability of measurable and non-measurable confounders.

\section{METHODS}

\section{Sample Selection}

We analyzed five panels (2009-2014) from the Medical Expenditure Panel Survey (MEPS) database [26] and selected individuals identified as having T2D and who utilized at least two antidiabetic drug medications for both years without intensifying or discontinuing the treatment, which would otherwise confound the analyses (see Supplementary Materials for details). We assumed: (a) classes of diabetes medications acquired in the first year of the MEPS panel (during at least two rounds) should have been acquired in the second year of the panel and (b) drugs in the same class with the same mechanism of action were considered interchangeable and drugs in different classes as complements (add-on therapy) [27]. The role of the first-year data was to select the combination therapy sample of patients. The second-year data were used for the analyses. For brevity, we refer to medication class as medication.

This study was conducted with secondaryuse, publicly available, and de-identified data. MEPS has been reviewed and approved by the Westat IRB, established under a multi-project assurance (MPA M-1531) granted by the Office for Protection from Research Risks (OPRR). The project is reviewed, and the approval is renewed annually.

\section{Measures of OOP Expenditures}

The last purchase in the second year was used to calculate OOP spending per day supplied (see Supplementary Materials for details) [27]. The medication classes with highest and lowest OOP costs per day were selected for each patient and difference in OOP costs $(\triangle \mathrm{OOP})$ and difference in medication possession ratio $(\triangle \mathrm{MPR})$ were calculated. As a result of the skewed distribution of $\triangle \mathrm{OOP}$, we defined ten categories, from low to 
high $\triangle$ OOP. The ten deciles were further categorized as least OOP cost difference group (least $\Delta$ OOP), moderate OOP cost difference group (moderate $\Delta \mathrm{OOP}$ ), and large OOP cost difference group (large $\triangle \mathrm{OOP}$ ) with the cost difference cutoff determined post hoc on the basis of adherence patterns.

\section{Measure of Adherence}

We measured adherence using MPR, which was defined as the days' supply divided by 365 days in a year, subtracted by any nights spent in the hospital as an inpatient. Generally, quantity of medication dispensed (e.g., number of pills) was available in MEPS, but days' supply contained missing values. Therefore, for each National Drug Code (NDC), median days per unit from 2010 to 2014 was calculated to impute missing days' supply [27]. All days' supplies were summed over their second MEPS year for all medications in the same class. If the summed days' supply was greater to or equal to 365 days (minus any nights spent in the hospital as an inpatient), the MPR was assigned a value of 1.0.

Two variables were derived using MPR. First, $\triangle M P R$ was defined as the difference between the MPR of the most costly OOP medication and that of the least costly OOP medication with a minimum and maximum $\triangle \mathrm{MPR}$ of -1 and + 1. Second, a categorical variable for adherence behavior was defined. When a conventional cutoff was used, a patient was considered adherent to a medication if his/her MPR was $\geq 80 \%$. As adherence to two medications were examined at the same time for each patient, the adherence behavior variable had four types: (a) "adhere to both" had MPR $\geq 80 \%$ for both most and least costly medications; (b) "adhere to neither" had MPR $<80 \%$ for both medications; (c) "adhere to the most costly medication" had MPR $\geq 80 \%$ for only the most costly medication; and (d) "adhere to the least costly medication" had MPR $\geq 80 \%$ for only the least costly medication.

\section{Statistical Analysis}

To understand whether and how patient adherence varied by the OOP cost difference $(\triangle \mathrm{OOP})$ between the medications (the primary hypothesis), a univariate regression was performed with $\triangle \mathrm{MPR}$ as the dependent variable and deciles of $\triangle O O P$ cost as the independent variable. Based on a post hoc examination of the results, a complex survey version of the Brown-Forsythe test [28] was performed to determine whether the variability of the $\triangle \mathrm{MPR}$ among patients increased as the $\triangle O O P$ between medications increased. If the patients treated the two medications in their combination therapy as complements, $\triangle \mathrm{MPR}$ would not be responsive to $\triangle \mathrm{OOP}$ cost.

A logistic multinomial model was employed to further understand which factors influenced the patients' adherence behavior to their combination therapy. The reference group was the group adherent to both most and least costly medications. For the selection of the independent variables, exploratory hypothesis-generating classification and regression tree (CART), as well as canonical discriminant analyses were first performed (further details and results in the Supplementary Materials).

Estimates were design-based using the strata, clusters, and weights of the complex survey design. Continuous variables and percentages were expressed as mean $\pm \mathrm{SE}$, except for scatter plots of OOP costs that utilized geometric means owing to skewness. Analysis were performed in SAS version 14.1 and $\mathrm{JMP}^{\circledR}$ version 13.1 (SAS Institute Inc., Cary, NC, USA).

\section{RESULTS}

\section{Demographics and Socioeconomic Characteristics}

A sample of 1189 patients were identified, representing 4,294,336 US patients with T2D on combination therapy (Table S1). Their average age was $62.4 \pm 0.5$ years (Table 1 ). Mean family income for first year was $\$ 51,845 \pm \$ 2078$ (median $\$ 39,660$ ). The average OOP cost for prescription medications in year 1 was 
Table 1 Summary statistics of the patient characteristics, adherence (MPR), and out-of-pocket (OOP) costs among the overall selected population and within patient subgroups based on the difference in OOP between their most and least costly diabetes medication class

\begin{tabular}{|c|c|c|c|c|}
\hline Variables & $\begin{array}{l}\text { Least } \triangle \mathrm{OOP}^{\mathrm{a}} \\
\text { Mean } \pm \mathrm{SE} \\
(\text { median) }\end{array}$ & $\begin{array}{l}\text { Moderate } \Delta \mathrm{OOP}^{\mathrm{a}} \\
\text { Mean } \pm \mathrm{SE} \\
(\text { median })\end{array}$ & $\begin{array}{l}\text { High } \triangle \mathrm{OOP}^{\mathrm{a}} \\
\text { Mean } \pm \mathrm{SE} \\
(\text { median) }\end{array}$ & $\begin{array}{l}\text { Overall } \\
\text { Mean } \pm \text { SE } \\
\quad \text { (median) }\end{array}$ \\
\hline$n$ & 488 & 506 & 195 & 1189 \\
\hline Weighted $n^{\mathrm{b}}$ & $1,609,887$ & $1,885,276$ & 799,173 & $4,294,336$ \\
\hline Age, years ${ }^{c}$ & $63.55 \pm 0.66(63.26)$ & $61.06 \pm 0.68(61.05)$ & $63.39 \pm 1.10(62.93)$ & $62.43 \pm 0.46(62.15)$ \\
\hline Sex $(\text { male })^{c}, \%$ & $45.91 \pm 3.07$ & $53.26 \pm 2.71$ & $53.80 \pm 4.25$ & $50.61 \pm 1.87$ \\
\hline $\mathrm{BMI}^{\mathrm{c}}, \mathrm{kg} / \mathrm{m}^{2}$ & $32.60 \pm 0.44(31.12)$ & $32.60 \pm 0.35(32.34)$ & $32.91 \pm 0.64(31.90)$ & $32.66 \pm 0.26(31.91)$ \\
\hline Age at $T 2 D$ diagnosis, years ${ }^{c}$ & $51.33 \pm 0.68(50.97)$ & $48.83 \pm 0.65(49.12)$ & $50.66 \pm 1.24(49.76)$ & $50.11 \pm 0.48(49.55)$ \\
\hline Family size ${ }^{c}, n$ & $2.27 \pm 0.08(1.42)$ & $2.27 \pm 0.07(1.54)$ & $2.24 \pm 0.11(1.51)$ & $2.27 \pm 0.05(1.49)$ \\
\hline Family total income $(\text { year } 1)^{c}, \$$ & $\begin{array}{l}41,853 \pm 2451 \\
(29,522)\end{array}$ & $\begin{array}{l}53,277 \pm 2426 \\
(43,716)\end{array}$ & $\begin{array}{l}68,598 \pm 6678 \\
(51,653)\end{array}$ & $\begin{array}{l}51,845 \pm 2078 \\
(39,660)\end{array}$ \\
\hline Duration of $\mathrm{T}^{2} \mathrm{D}^{\mathrm{c}}$, years & $13.10 \pm 0.45(11.51)$ & $13.14 \pm 0.54(10.54)$ & $13.64 \pm 0.86(11.31)$ & $13.22 \pm 0.31(11.13)$ \\
\hline SF-12 $\mathrm{MCS}^{\mathrm{c}}$ & $48.86 \pm 0.63(51.28)$ & $49.56 \pm 0.62(51.12)$ & $50.52 \pm 1.12(53.45)$ & $49.47 \pm 0.42(51.46)$ \\
\hline SF-12 PCS & $38.46 \pm 0.71(38.63)$ & $40.17 \pm 0.68(42.39)$ & $40.76 \pm 1.00(41.32)$ & $39.63 \pm 0.48(40.72)$ \\
\hline \multicolumn{5}{|l|}{ Health expenditures at year 1} \\
\hline Total Rx expenditures, \$ & $\begin{array}{l}3821.9 \pm 317.1 \\
\quad(2222.0)\end{array}$ & $\begin{array}{l}4443.3 \pm 357.4 \\
(2908.4)\end{array}$ & $\begin{array}{l}4996.0 \pm 382.2 \\
\quad(3573.8)\end{array}$ & $\begin{array}{l}4313.2 \pm 228.2 \\
(2897.0)\end{array}$ \\
\hline $\begin{array}{l}\text { Total OOP }{ }^{\mathrm{d}} \mathrm{Rx} \text { cost (all } \\
\text { medicines), } \$\end{array}$ & $\begin{array}{l}661.9 \pm 158.5 \\
(262.1)\end{array}$ & $839.6 \pm 59.6(526.8)$ & $\begin{array}{l}1316.4 \pm 127.5 \\
\quad(923.1)\end{array}$ & $861.7 \pm 69.7(475.4)$ \\
\hline Total OOP $^{\mathrm{d}}$ cost, $\$$ & $\begin{array}{l}1296.4 \pm 204.4 \\
\quad(507.7)\end{array}$ & $\begin{array}{l}1443.6 \pm 106.8 \\
(963.4)\end{array}$ & $\begin{array}{l}1885.1 \pm 139.3 \\
\quad(1466.9)\end{array}$ & $\begin{array}{l}1470.6 \pm 92.7 \\
(886.3)\end{array}$ \\
\hline Total healthcare expense, \$ & $\begin{array}{l}11,547.0 \pm 938.2 \\
\quad(5968.5)\end{array}$ & $\begin{array}{l}12,609.6 \pm 1023.9 \\
\quad(6236.9)\end{array}$ & $\begin{array}{l}10,737.3 \pm 958.6 \\
\quad(7258.1)\end{array}$ & $\begin{array}{l}11,862.8 \pm 629.7 \\
(6418.9)\end{array}$ \\
\hline Number of nights in hospital, $n$ & $0.90 \pm 0.16(0.00)$ & $1.19 \pm 0.25(0.00)$ & $0.75 \pm 0.19(0.00)$ & $1 \pm 0.13(0.00)$ \\
\hline \multicolumn{5}{|l|}{ Adherence to medication } \\
\hline $\begin{array}{l}\text { MPR for most costly medication } \\
\text { class }(\%)\end{array}$ & $78.4 \pm 1.4(90.9)$ & $69.1 \pm 1.6(73.7)$ & $62.5 \pm 2.8(63.8)$ & $71.3 \pm 1.2(74.6)$ \\
\hline $\begin{array}{l}\text { MPR for least costly medication } \\
\text { class }(\%)\end{array}$ & $77.5 \pm 1.7(88.5)$ & $76.5 \pm 1.6(95.3)$ & $76.7 \pm 2.3(86.9)$ & $76.9 \pm 1.0(89.9)$ \\
\hline$\triangle \mathrm{MPR}(\%)$ & $0.9 \pm 1.4(-0.3)$ & $-7.5 \pm 1.9(0.0)$ & $\begin{aligned}- & 14.2 \pm 3.7 \\
& (-13.7)\end{aligned}$ & $-5.6 \pm 1.3(0.0)$ \\
\hline
\end{tabular}


Table 1 continued

\begin{tabular}{|c|c|c|c|c|}
\hline Variables & $\begin{array}{l}\text { Least } \triangle \mathrm{OOP}^{\mathrm{a}} \\
\text { Mean } \pm \mathrm{SE} \\
\quad(\text { median })\end{array}$ & $\begin{array}{l}\text { Moderate } \\
\Delta \text { OOP }^{\mathrm{a}} \\
\text { Mean } \pm \mathrm{SE} \\
\quad(\text { median })\end{array}$ & $\begin{array}{l}\text { High } \triangle O O P^{a} \\
\text { Mean } \pm S E \\
\quad(\text { median })\end{array}$ & $\begin{array}{l}\text { Overall } \\
\text { Mean } \pm \text { SE } \\
\quad(\text { median })\end{array}$ \\
\hline \multicolumn{5}{|l|}{ MPR pattern for most and least costly medication class ${ }^{\mathrm{e}}$} \\
\hline $\begin{array}{l}\geq 80 \% \text { for both most costly and least costly } \\
\text { medication classes }\end{array}$ & $43.9 \pm 3.3$ & $31.2 \pm 2.3$ & $25.6 \pm 4.2$ & $34.9 \pm 1.9$ \\
\hline $\begin{array}{l}<80 \% \text { for both most costly and least costly } \\
\text { medication classes }\end{array}$ & $27.4 \pm 2.6$ & $28.9 \pm 2.5$ & $30.5 \pm 4.0$ & $28.7 \pm 1.7$ \\
\hline$\geq 80 \%$ for only the most costly medication class & $15.0 \pm 2.2$ & $12.6 \pm 2.1$ & $12.8 \pm 2.9$ & $13.5 \pm 1.4$ \\
\hline$\geq 80 \%$ for only the least costly medication class & $13.7 \pm 2.3$ & $27.3 \pm 2.5$ & $31.1 \pm 4.2$ & $22.9 \pm 1.6$ \\
\hline \multicolumn{5}{|l|}{ OOP $\operatorname{cost}^{\mathrm{f}}$ (last prescription) } \\
\hline For most costly medication class $(\$)$ & $\begin{array}{l}5.73 \pm 0.48 \\
(3.47)\end{array}$ & $\begin{array}{l}27.35 \pm 1.27 \\
(19.53)\end{array}$ & $\begin{array}{l}177.60 \pm 26.97 \\
\quad(112.68)\end{array}$ & $\begin{array}{l}47.21 \pm 5.59 \\
(12.37)\end{array}$ \\
\hline For least costly medication class $(\$)$ & $\begin{array}{l}5.45 \pm 0.46 \\
(2.52)\end{array}$ & $\begin{array}{l}7.79 \pm 0.60 \\
\quad(4.88)\end{array}$ & $9.88 \pm 1.10(5.99)$ & $\begin{array}{l}7.30 \pm 0.41 \\
(4.19)\end{array}$ \\
\hline OOP cost/day for most costly medication class $(\$)$ & $\begin{array}{l}0.10 \pm 0.01 \\
\quad(0.08)\end{array}$ & $\begin{array}{l}0.54 \pm 0.02 \\
\quad(0.44)\end{array}$ & $4.53 \pm 0.88(2.37)$ & $\begin{array}{l}1.12 \pm 0.18 \\
(0.28)\end{array}$ \\
\hline $\begin{array}{l}\text { OOP cost/day for least costly last medication class } \\
(\$)\end{array}$ & $\begin{array}{l}0.08 \pm 0.01 \\
\quad(0.04)\end{array}$ & $\begin{array}{l}0.14 \pm 0.01 \\
\quad(0.11)\end{array}$ & $0.19 \pm 0.02(0.12)$ & $\begin{array}{l}0.12 \pm 0.01 \\
\quad(0.09)\end{array}$ \\
\hline$\Delta \mathrm{OOP} /$ day $(\$)$ & $\begin{array}{l}0.02 \pm 0.00 \\
(0.00)\end{array}$ & $\begin{array}{l}0.41 \pm 0.02 \\
\quad(0.31)\end{array}$ & $4.34 \pm 0.88(2.30)$ & $\begin{array}{l}0.99 \pm 0.18 \\
(0.16)\end{array}$ \\
\hline
\end{tabular}

$B M I$ body mass index, CART classification and regression tree, MCS mental component summary, MPR medication possession ratio, $n$ number of MEPS participants in each category, $O O P$ out-of-pocket, $P C S$ physical component summary, $R x$ prescription, $S E$ standard error, $S F-12$ 12-item short form health survey, $T 2 D$ type 2 diabetes

a The distribution of OOP cost difference $(\Delta \mathrm{OOP})$ was grouped in 10 deciles, which were categorized as least $\Delta \mathrm{OOP}$ group ( $\$ 0-$ $2.39 /$ month), moderate $\Delta$ OOP group (\$2.39-32.98/month), and large $\Delta$ OOP group (\$32.98-61.45/month)

b Weighted $n$ utilizes person-specific sampling weights based on the US census to adjust for the complex sample design and non-response, for an estimate of the US non-institutionalized group size

c Included as independent variable in CART to predict adherence status

d All OOP costs were first converted to 2014 values using the MEPS OOP expenditures guideline of Consumer Price index

e Dependent variable in CART analysis

${ }^{\mathrm{f}}$ Included as independent variable in CART to predict adherence status. The last purchase in the second year was used to calculate OOP. Using the last purchase minimizes the chance that OOP spending is under, for example, a deductible

$\$ 862 \pm \$ 70$ (median $\$ 475$ ) and OOP cost for all healthcare was $\$ 1471 \pm \$ 93$ (median $\$ 886$ ).

\section{Summary Statistics of OOP Costs and Adherence Behavior}

As described in Table 1, the mean OOP cost per day for the most costly medication was $\$ 1.1 \pm \$ 0.2$ per day (median $\$ 0.3$ ) and for the 
least costly medication was $\$ 0.12 \pm \$ 0.01$ per day (median \$0.09). The mean OOP cost difference $(\triangle \mathrm{OOP})$ was $\$ 0.99 \pm \$ 0.18$ per day (median \$0.16). Across the entire sample, the mean MPR for the most costly medication was $71.3 \% \pm 1.2 \%$ (median $74.6 \%$ ) and for the least costly medication was $76.9 \% \pm 1.0 \%$ (median $89.9 \%)$. In the least $\Delta$ OOP group, the adherence to the least costly medication was $77.5 \%$ and for most costly medication it was $78.4 \%$, with only a mean $\triangle$ OOP cost of $\$ 0.02 /$ day. As the mean $\Delta$ OOP cost increased to $\$ 0.41 /$ day for the moderate $\triangle \mathrm{OOP}$ group, the MPR dropped very slightly to $76.5 \%$ for least costly medication but considerably more for the most costly medication to $69.1 \%$. In the high $\Delta$ OOP group, with a mean $\triangle$ OOP of $\$ 4.34 /$ day, the MPR for least costly medication remained approximately the same $(76.7 \%)$, whereas the MPR for most costly medication dropped to $62.5 \%$. Regardless of the increase in $\triangle \mathrm{OOP}$ cost, MPR for least costly medication averaged about $77 \%$ over a year for all three $\triangle O O P$ groups, but, that for the most costly medication dropped by $15.9 \%$ from the least $\Delta \mathrm{OOP}$ group to the highest $\Delta \mathrm{OOP}$ group. The mean $\triangle \mathrm{MPR}$ for the least $\triangle \mathrm{OOP}$ group was near zero $(0.9 \% \pm 1.4 \%)$ indicating equal adherence to both medications, whereas the corresponding adherence difference for the highest $\triangle$ OOP group was $-14.2 \% \pm 3.7 \%$.

The $\triangle$ OOP cost is skewed toward $\$ 0$, with few outliers of very high $\Delta O O P$ cost difference (Fig. 1a). In contrast, $\triangle$ MPR is relatively symmetric, with $28.5 \%$ of patients having the same adherence level to their medications regardless of OOP cost (Fig. 1b). Overall, patients tended to lean toward more adherent to their least costly medication with $42.5 \%$ patients more adherent to the least costly medication and $29.0 \%$ patients more adherent to the most costly medication. About $34.9 \%$ of the patients had $\geq 80 \%$ MPR for both least and most costly medications, $28.7 \%$ had $<80 \%$ MPR for both medications, $22.9 \%$ had $\geq 80 \%$ MPR for only the least costly medication, and $13.5 \%$ had $\geq 80 \%$ MPR for only the most costly medication. Therefore, $57.8 \%$ of the patients exceeded $80 \%$ MPR for their least costly medication and $48.4 \%$ had $\geq 80 \%$ MPR for the most costly medication.

\section{Primary Analysis: Correlation Between $\triangle \mathrm{OOP}$ Costs and $\triangle \mathrm{MPR}$}

The $\Delta \mathrm{OOP}$ was significantly negatively correlated with the $\triangle \mathrm{MPR}$ (Fig. 2). On the basis of the significant slope $(p<0.001)$, for every increase in $\triangle \mathrm{OOP}$ decile $(\Delta \mathrm{OOP} /$ day increase ranging from $\$ 0.03$ to $\$ 0.93$ increase in each decile), the $\triangle \mathrm{MPR}$ decreased on average by $1.8 \% \pm 0.4 \%$ $(p<0.001)$. Noting the shaded region of Fig. 2 along the $\mathrm{x}$-axis, the mode within each level of $\triangle O O P$, the mode of patients adhered to both medications approximately equally, although this number decreased as the $\triangle O O P$ in each decile increased.

As the $\triangle \mathrm{OOP}$ increased, the variability in $\triangle$ MPR markedly increased (Fig. 3), which was confirmed by the post hoc Brown-Forsythe test $(p<0.001)$. Figure 3 illustrates the $\Delta$ OOP groups that were defined post hoc. The first three OOP cost deciles were categorized as least $\triangle$ OOP group because within this group the boxes that represent the middle $50 \%$ of the distribution (25th to 75 th percentile) were relatively narrow; most individuals had similar adherence to their most and least costly medication if their OOP cost differed by less than \$0.078/day (Fig. 3 inset table). The next five deciles were categorized as moderate $\triangle \mathrm{OOP}$ group whose $\Delta$ OOP costs ranged from $\$ 0.08$ to $\$ 1.08$ per day. The median $\triangle \mathrm{MPR}$ was near zero, with $29.0 \%$ of patients having no difference in adherence, $28.5 \%$ being more adherent to the most costly medication, while $42.5 \%$ of them being more adherent to the least costly medication. However, the sizes of the boxes in the plot increased compared to the least $\Delta \mathrm{OOP}$ group, indicating increased variability in $\triangle \mathrm{MPR}$. Compared to the least $\Delta$ OOP group, while there was no distinct shift to the least costly medication, adherence choices became more variable in response to the increase in the $\Delta \mathrm{OOP}$ between the medications and fewer patients had equal adherence to both medications. The last two cost deciles were categorized as large $\triangle$ OOP group which has patients with $\triangle$ OOP costs exceeding $\$ 1.08 /$ day or $\$ 32.98 /$ month. The mean and median $\triangle \mathrm{MPR}$ in this group decreased, shifting adherence towards the least costly medication away from the most costly 

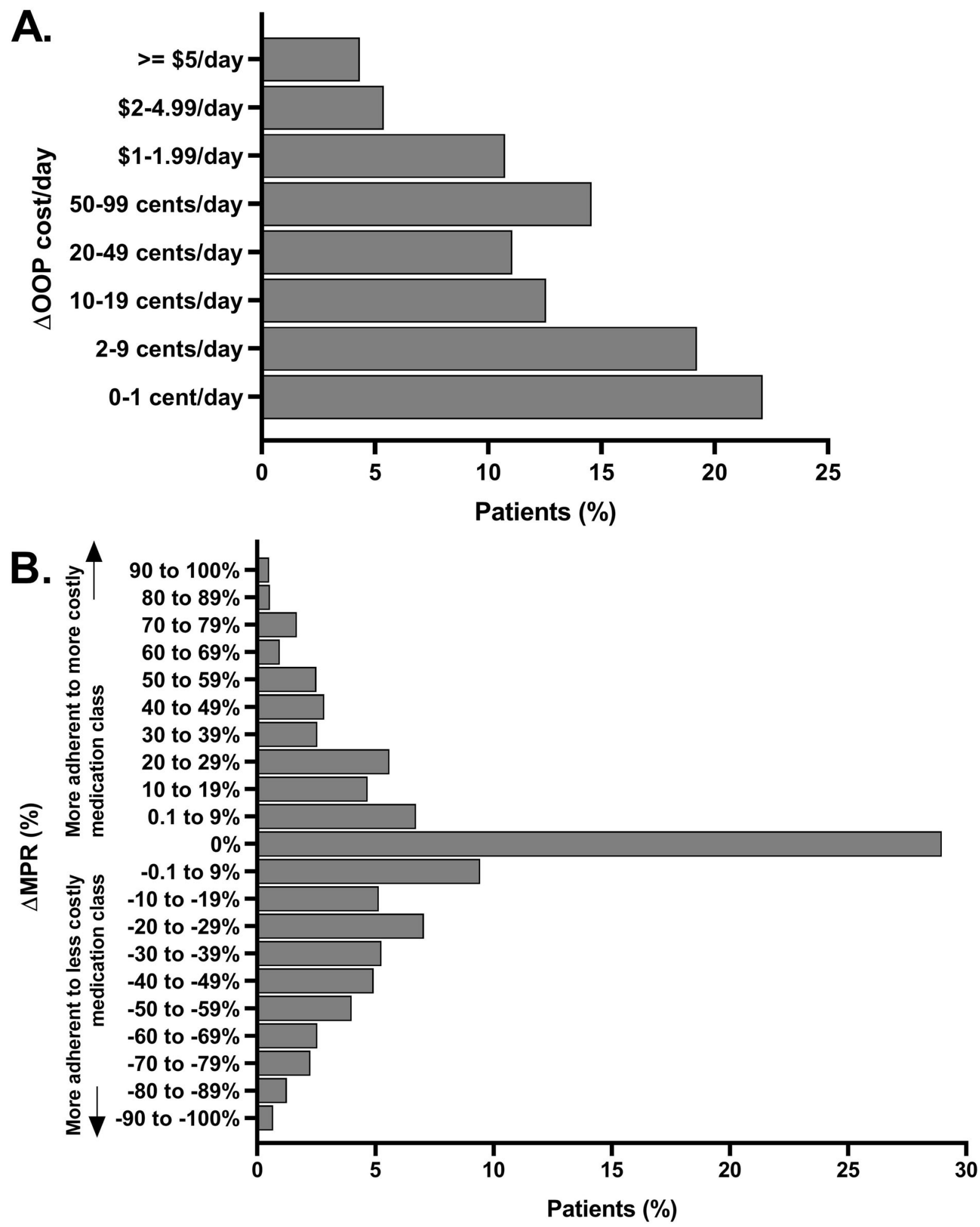
4 Fig. 1 Distribution of a out-of-pocket cost difference between most and least costly medication class per day $(\triangle \mathrm{OOP}$ costs/day) and $\mathbf{b}$ difference in medication possession ratio (adherence) between most and least costly medication class $(\triangle \mathrm{MPR})$. MPR medication possession ratio, OOP out-of-pocket

medication. In this group, the top five most commonly used medications that contributed most to the highest OOP cost medication and to the least costly OOP medication class are listed in Table S2.

\section{Factors Affecting Adherence Behavior}

A multinomial logistic regression identified three variables that significantly affected adherence behavior. These included the ratio of daily OOP between the least and the most costly medications (relative OOP; $p=0.002$ ), whether most costly medication type was an insulin and/or fixed-dose combination (FDC) $(p=0.006)$, and Short-Form-12 physical component summary (PCS) score in previous year (baseline health status; $p=0.006$; Table 2). The Supplementary Material illustrates that CART of $\triangle$ MPR dichotomized the classes into insulin or FDC versus all others, hence their grouping here. In contrast to the ratio, the sum of the OOP costs per day for both the least and most costly medications (OOP sum/total) was not statistically significant overall $(p=0.13)$, it played a significant role defining the not-adherent-to-either medication group. Other variables that did not significantly affect adherence when added to the multinomial model included education $(p=0.18)$, number of diabetes medications $(p=0.84)$, primary cardiovascular $(\mathrm{CV})$ disease risk with hypertension $(p=0.24)$, primary $\mathrm{CV}$ disease risk with hypercholesterolemia (0.87), secondary $\mathrm{CV}$ risk $(p=0.20)$, family income $(p=0.94)$, age $(p=0.69)$, gender $(p=0.34)$, and insurance status $(p=0.49)$.

For those patients adherent only to the least costly medication, as the relative OOP increased by $10 \%$ (i.e., $\triangle \mathrm{OOP}$ reduced/cost difference becomes smaller), the odds of only being adherent to the least costly medication decreases (odds ratio (OR) $\left[\begin{array}{lll}95 \% & \mathrm{CI}\end{array}\right], 0.90$ $[0.84-0.96] ; p=0.002)$. For those patients in the less frequent "adherent to only the most costly medication" group, the key factor associated with this behavior is whether the most costly medication is an insulin or FDC, which increased the odds of being in this group to 1.91 (OR [95\% CI] 1.20-3.04; $p=0.007$ ). The odds of being a patient not adherent to either medication increased as the OOP sum doubled (OR [95\% CI] 1.40 [1.06-1.86]; $p=0.02$ ). As the previous year's SF-12 PCS score increased, indicating better patient perception of their baseline physical functional status, the odds of being non-adherent to both medications increased (OR $[95 \%$ CI $]$ per 5-point PCS increase, 1.16 [1.07-1.26]; $p<0.001)$. Replacing this significant variable with a five-level self-reported health score or a comorbidity score in the regression yielded the same result. Although the increase in SF-12 PCS score did not reach statistical significance, it appeared to be associated with improved odds of adherence to the least costly medication ( $\mathrm{OR}=1.08 ; p=0.08$ ). Further details are provided in the Supporting Material.

\section{DISCUSSION}

This study examined the association between the adherence behavior to combination therapy and the relative difference in the OOP costs for patients with T2D on multiple antidiabetic medications. As expected, the association was negative, with adherence shifting towards least costly medication as the OOP cost difference increased. As per our expectation, as the difference in OOP costs increased, we observed a proportional/gradual decrease in adherence to the more costly medication. However, we found further nuances to this association. In combination therapy, adherence was similar for two medications with similar OOP costs. However, as OOP cost difference increased (between $\$ 2.39 /$ month and $\$ 33 /$ month), even though the median difference adherence did not shift adherence away from the most costly medication, the between-medication variability of adherence increased. At this moderate OOP cost 


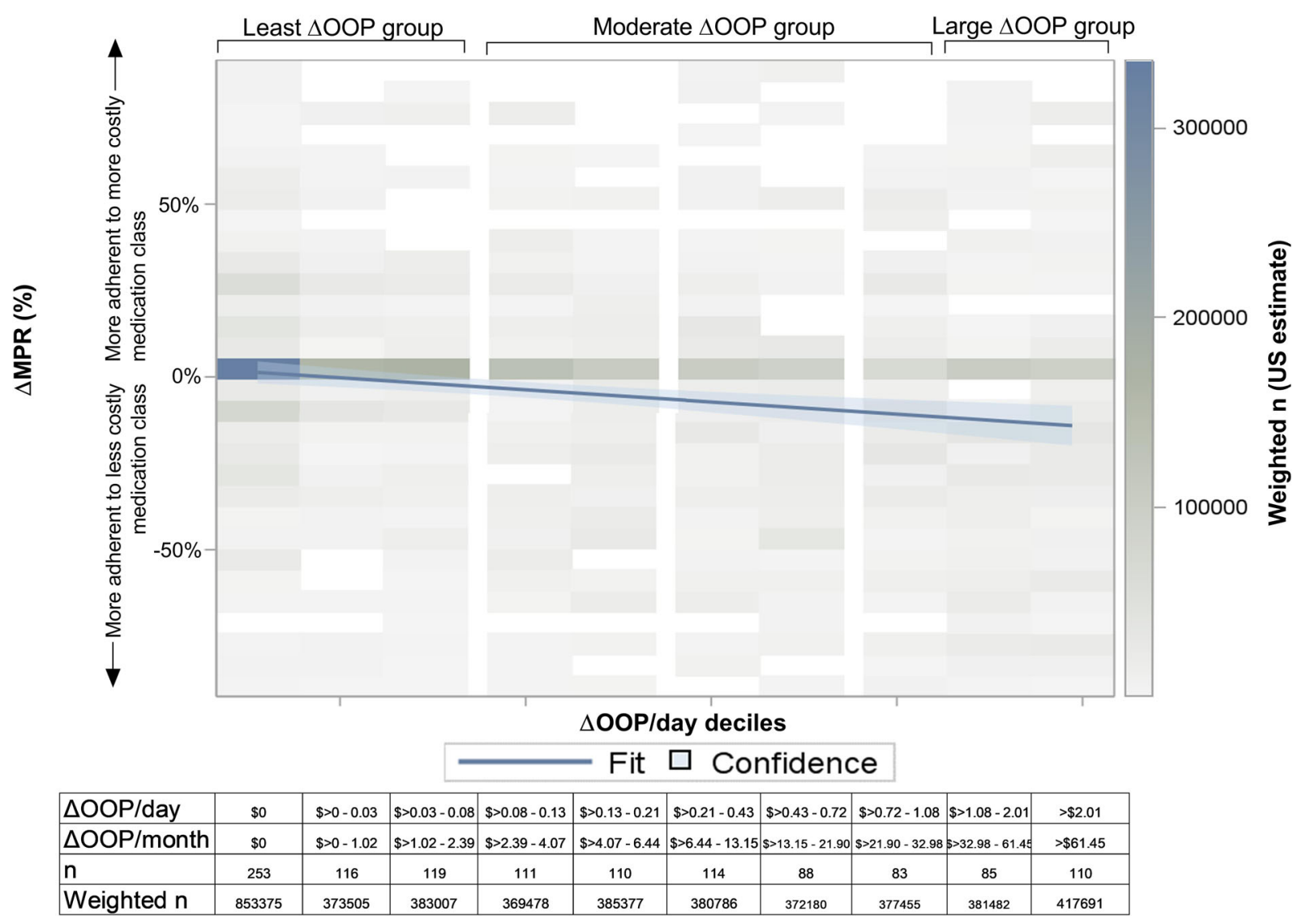

Fig. 2 Correlation between differences in OOP and adherence between patients' least and most costly medication. The thick blue line indicates the regression line along with the blue shaded part indicating 95\% confidence

difference, patients might favor either the most or least costly medication depending on patient characteristics such as medication prescribed and health status. However, beyond $\$ 33 /$ month of $\triangle \mathrm{OOP}$ cost, we observed our a priori expectation of reduced adherence for the most costly medication. High OOP cost difference eventually emerged as the dominating factor leading more patients to significantly reduce consumption of the most costly medications, disregarding the intended complementary nature of the medications in a combination therapy.

The main justification for higher demandside cost-sharing is that the "moral hazard" (incentive to take unusual risks because others bear the economic consequences) that comes with generous insurance encourages overconsumption of medical care $[7,29,30]$. The widely interval. The gray-to-blue shading corresponds to the weighted $\mathrm{n}$ on the second $\mathrm{y}$-axis. MPR medication possession ratio, OOP out-of-pocket

adopted remedy for this is to trade off the benefits of risk spreading (insurance) against the costs of moral hazard by transferring risk to insured individuals using the form of higher demand-side cost-sharing [6]. This theory further postulated that cost-sharing would only discourage the consumption of the low efficiency or unnecessary medical services because the rational utility-maximizing consumers would demand medical care to the point where marginal costs equals marginal benefits. But this remedy could result in unintended effects if the design of cost-sharing does not recognize the heterogenous disease characteristics, treatment patterns, or patient needs. As T2D is a progressive disease, combination therapy becomes necessary for glycemic control, especially for patients with a longer duration of diabetes [15]. 


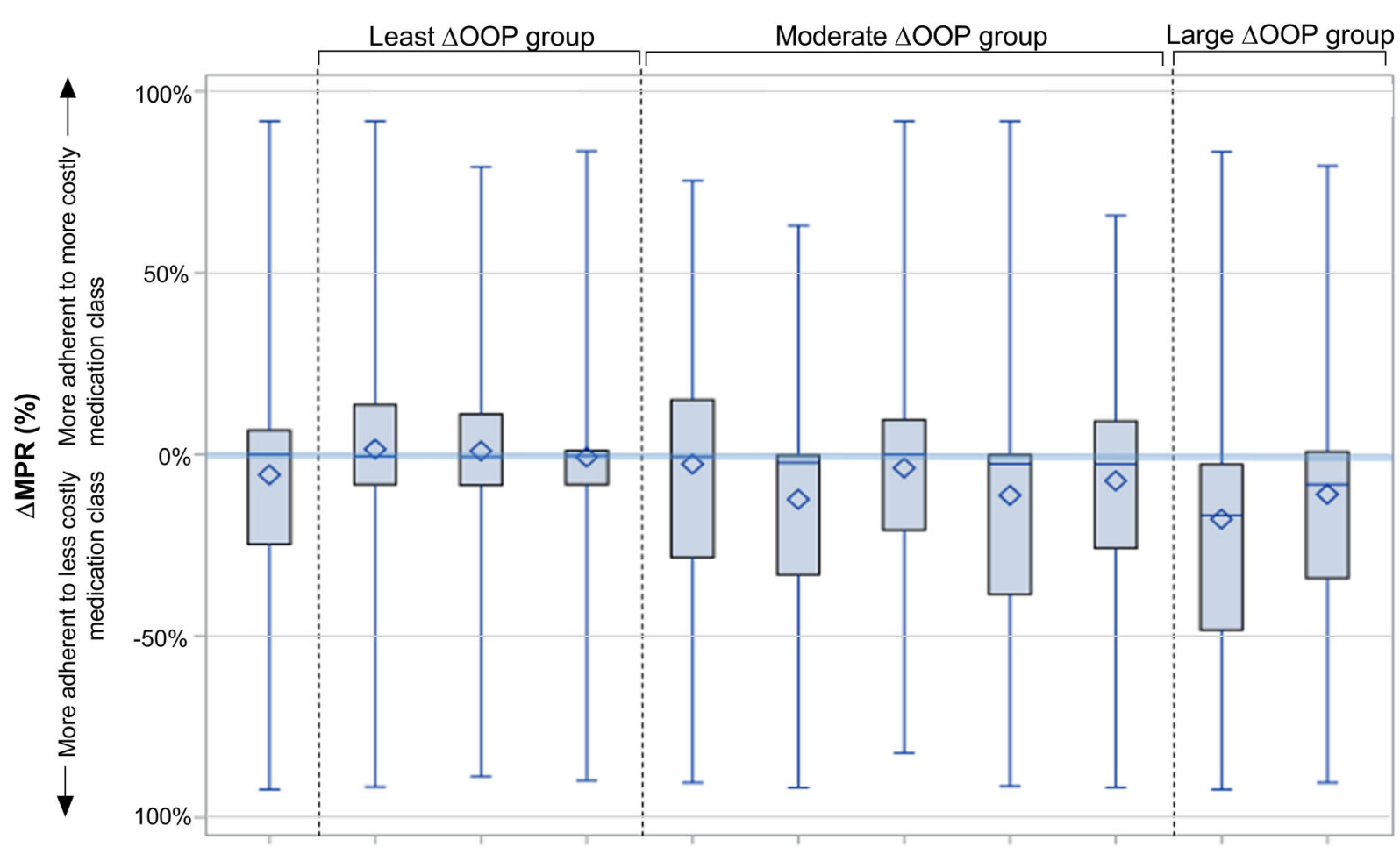

$\triangle O O P /$ day decile

\begin{tabular}{|l|l|c|c|c|c|c|c|c|c|c|c|}
\hline$\Delta$ OOP/day & Full Sample & $\$ 0$ & $\$>0-0.03$ & $\$>0.03-0.08$ & $\$>0.08-0.13$ & $\$>0.13-0.21$ & $\$>0.21-0.43$ & $\$>0.43-0.72$ & $\$>0.72-1.08$ & $\$>1.08-2.01$ & $>\$ 2.01$ \\
\hline$\Delta$ OOP/month & Full Sample & $\$ 0$ & $\$>0-1.02$ & $\$>1.02-2.39$ & $\$>2.39-4.07$ & $\$>4.07-6.44$ & $\$>6.44-13.15$ & $\$>13.15-21.90$ & $\$>21.90-32.98>>32.98-61.45$ & $>\$ 61.45$ \\
\hline
\end{tabular}

Fig. 3 Variability in difference in the adherence between medication class $(\triangle \mathrm{MPR})$ by decile of out-of-pocket cost difference $(\Delta \mathrm{OOP})$. The box indicates the 25 th and 75 th

Many patients eventually need to use injectables in combination with oral medications. For them, the medications in the prescribed combination regimen are complements to each other rather than substitutes, i.e., all components in the combination therapy are considered effective and necessary. Therefore, adherence to all the components in a combination regimen should be equally observed for optimal glucose control.

Yet, our study highlights that patients made heterogeneous treatment adherence decisions when faced with different OOP costs for their medications. Nearly a quarter of the studied patients appeared to forgo the more costly medication in favor of the least costly medication when the OOP cost difference was large enough, despite the necessity to adhere to all the medicines of the combination therapy. For percentiles, the blue line within the box indicates the median, and the diamond indicates the mean. MPR medication possession ratio, OOP out-of-pocket

these patients, OOP cost consideration appeared to outweigh the medical necessity as their relative OOP cost was the most significant variable that impacted the adherence decisions. One possible explanation could be that some patients did not have the necessary experience or information for their medical decisions, as suggested by Rice [9], and therefore treated the complementary medicines in a combination therapy as if they were perfect substitutes. The RAND Health Insurance Experiment (HIE) [31] also found that patients reduced their consumption of both effective and less effective medical services when faced with cost-sharing. This elastic adherence behavior to OOP costs is concerning and could have negative health consequences for this subgroup of patients if treatment regimen is not adhered to as prescribed. 
Table 2 Multinomial logistic regression to examine risk factors for adherent to the least costly, most costly, or both classes of medications ${ }^{\mathrm{a}}$ (adherent to both is reference group)

\begin{tabular}{|c|c|c|c|c|c|c|c|}
\hline \multirow[t]{2}{*}{ Variable } & \multicolumn{2}{|c|}{$\begin{array}{l}\text { Adherent to least } \\
\text { OOP cost medication } \\
\text { class }(n=260 \\
\text { weighted } \\
n=983,600)\end{array}$} & \multicolumn{2}{|c|}{$\begin{array}{l}\text { Adherent to highest } \\
\text { OOP cost medication } \\
\text { class }(n=170 \text {; } \\
\text { weighted } \\
n=581,287)\end{array}$} & \multicolumn{2}{|c|}{$\begin{array}{l}\text { Not adherent to both } \\
\text { medication classes } \\
(n=346 ; \text { weighted } \\
n=1,230,184)\end{array}$} & \multirow[t]{2}{*}{$\begin{array}{l}\text { Overall } \\
p \text { value }\end{array}$} \\
\hline & $\begin{array}{l}\text { OR }(95 \% \\
\text { CI })\end{array}$ & $p$ value & $\begin{array}{l}\text { OR }(95 \% \\
\text { CI) }\end{array}$ & $p$ value & $\begin{array}{l}\text { OR }(95 \% \\
\text { CI })\end{array}$ & $p$ value & \\
\hline $\begin{array}{l}\text { OOP per day sum }{ }^{\mathrm{b}} \text { of least and } \\
\text { most costly medication class }\end{array}$ & $\begin{array}{l}1.23 \\
\quad(0.95-1.58)\end{array}$ & 0.12 & $\begin{array}{l}1.21 \\
\quad(0.85-1.72)\end{array}$ & 0.28 & $\begin{array}{l}1.40 \\
(1.06-1.86)\end{array}$ & 0.02 & 0.13 \\
\hline $\begin{array}{l}\text { OOP per day ratio }{ }^{c} \text { (least/most } \\
\text { costly medication class) }\end{array}$ & $\begin{array}{l}0.90 \\
\quad(0.84-0.96)\end{array}$ & 0.002 & $\begin{array}{l}1.04 \\
\quad(0.97-1.11)\end{array}$ & 0.25 & $\begin{array}{l}1.01 \\
\quad(0.96-1.07)\end{array}$ & 0.66 & 0.002 \\
\hline $\begin{array}{l}\text { Most costly medication is } \\
\text { insulin or FDC }\end{array}$ & $\begin{array}{l}0.92 \\
\quad(0.55-1.52)\end{array}$ & 0.73 & $\begin{array}{l}1.91 \\
\quad(1.20-3.04)\end{array}$ & 0.007 & $\begin{array}{l}0.8 \\
\quad(0.51-1.25)\end{array}$ & 0.32 & 0.006 \\
\hline SF-12 PCS ${ }^{\mathrm{d}}$ & $\begin{array}{l}1.08 \\
(0.99-1.17)\end{array}$ & 0.08 & $\begin{array}{l}1.08 \\
\quad(0.98-1.19)\end{array}$ & 0.11 & $\begin{array}{l}1.16 \\
(1.07-1.26)\end{array}$ & $<0.001$ & 0.006 \\
\hline
\end{tabular}

FDC fixed dose combination, $n$ number of MEPS participants in each category, OOP out-of-pocket, $O R$ odds ratio, $P C S$ physical composite scale, $S F-12$ 12-item short form health survey, weighted $n n$ utilizing person-specific sampling weights based on the US census

${ }^{a}$ Medication classes were defined using the Multum Lexicon therapeutic classification variable of sub-therapeutic classes within antidiabetes agents. This includes the subtherapeutic class of "antidiabetic combinations" FDC, which was treated as a single class in analyses, although FDC generally comprises multiple other subtherapeutic classes

${ }^{b}$ OR for OOP per day sum is based on base- 2 logarithm, so odds are based on $2 \times$ increase in OOP per day

${ }^{c}$ OR for OOP per day ratio is based on $10 \%$ increment increase in OOP per day ratio

d OR for SF-12 PCS is based on 5-point increase PCS. Reference group: adherent to both $(n=413$; weighted $n=1,499,265)$

It is evident that a third of the studied patients were equally adherent to their medications regardless of the OOP cost difference between medications, indicating the medications were treated as complements as they should be in combination therapies. More than one-eighth of the study population may have behaved like informed consumers who considered the medical effectiveness when making medical consumption decisions, as Rice [9] had theorized. For these patients adherent only to the most costly medication, the sole significant factor associated with this behavior was whether the most costly medication is an insulin or FDC. They might be driven by the perception that certain medication like insulin was important for their health [23]. Nevertheless, most costly medications were not necessarily the most effective and it was not optimal for this group of patients to be non-adherent to their combination therapy as prescribed by physicians.

In contrast to other patients, for nearly a third of the study population who were nonadherent to either of their medications in the combination therapy the relative OOP costs between the medications was not relevant. Instead, the overall OOP burden influenced their choice. Another finding among this group of patients was that patients with better selfperception of physical health had increased odds of being non-adherent to both medications. With perceived better health, patients might not feel the urgency to maintain 
adherence to medications at the $80 \%$ level, particularly if the overall medication burden was high. The lack of notable symptoms among patients with chronic conditions such as osteoporosis or diabetes could create a perception of low or even no risk of complications if medications were not used as prescribed $[32,33]$. It is therefore important to find ways to improve the adherence among these patients by reducing the overall OOP cost burden and through disease education. Reduced cost-sharing for preventive drugs may benefit low-income patients with diabetes in high-deductible health plans with a health savings account [34].

Our study showed that, in the USA, medication adherence in patients with T2D on combination therapy has not been ideal to begin with, let alone overconsumption of the medications. The adherence to the most costly medication averaged $78.4 \%$ within the group with near zero cost difference, while it was $62.5 \%$ for the high OOP cost difference group. More concerning is that only one-third of the patients were adherent to both medications in the combination therapy. Therefore, while the high cost-sharing strategies may be necessary to curb resource utilization in some area, the attempt of cost control scheme for prescription medications among patients with T2D (especially among those on combination therapy) might be misplaced. While previous reports clearly suggest that reduced cost-sharing for targeted prescription drugs is significantly associated with improved adherence [35], our study suggests that reducing the relative OOP cost difference between medications would matter significantly for the adherence to combination therapy. Given that the adherence behavior started to vary when difference in OOP costs between medications was as low as $\$ 2.39 /$ month, minimizing the OOP cost difference in tiered copay insurance design (which created the OOP cost difference between medications) or moving away from high-deductible design (which caused the high OOP cost difference during the early period in a given insured year) might be needed to improve adherence of patients with T2D to combination therapy.
Our study differed in several aspects from other studies in the research area of adherence and OOP cost relationship. First, each of the patients (observation) in this study was simultaneously faced with two OOP costs and two adherence decisions while in most other studies each patient (observation) was faced with one price and one adherence decision. Secondly, most other studies examined the relationship between adherence and the OOP cost using cross-sectional data, which is unable to account for the unobserved interpatient heterogeneity. Unaccounted variables such as the safety profile of prescribed medicines, general preferences for pharmaceutical, the seriousness of the illness, and the perceived effectiveness of the relevant medication may be important predictors of pharmaceutical demand. Failing to account for important predictors can lead to omitted variable bias [36, 37]. In our study, we reduced both observed and unobserved heterogeneity by using a paired within-patient approach for the primary analysis. To our knowledge, this is the only study that discusses how adherence responds to differences in OOP costs. Thirdly, we employed a design-based approach in selecting the variables that matter to the adherence pattern. Importantly, the variable list produced by this approach is consistent with the prediction of the economic theory [7] that demand for medications is determined by the relative prices (i.e., relative OOP costs) as well as a few other non-cost factors such as perceived health status and proxy for medication effectiveness. The use of relative OOP cost in the multinomial logistic regression reflected the trade-offs that patients had to consider in making treatment decisions. In most other retrospective analysis of drug demand, it was the OOP costs of the selected treatment rather than the relative OOP costs associated with the treatments that were considered [38].

Much evidence suggests that adherence is influenced by age, duration of therapy, education, income, prescription factors, and pill burden [22]. In contrast, we found factors such as number of diabetes medications, family income, age, gender, and insurance status did not significantly influence the adherence behavior. Education was an exception, which 
was marginally significant, consistent with other studies. These differences are likely due to the paired within-patient methodological approach taken in this study as well as the characteristics of the patients with T2D on combination therapy.

\section{Limitations}

Though patients selected for this study did not change their number of antidiabetic drug classes over the 2-year period (this was designed to minimize medication additions or discontinuations), we could not directly observe whether this was the case. In addition, we followed a published framework that estimated OOP cost derived from the last purchase of the calendar year. As a result of the complexity of plans in which collective OOP costs can change at any point during the year, we believe using the last OOP cost provides a reasonable approach, but we cannot determine how often that reflects the reality of their potential subsequent OOP cost. In addition, this study utilized self-reported information, which may be subject to reporting bias. We excluded patients who did not complete 2 years of MEPS participation, so those who died, dropped out, or were institutionalized during participation were not included. We cannot assess the impact of the burden of personal expenses outside the healthcare sector.

\section{CONCLUSIONS}

In the context of patients with T2D taking combination therapy, variability in medication adherence increases initially until a cost threshold, beyond which the adherence to more costly medication decreases. This suggests that adherence to combination therapy may be compromised by the heterogeneous sensitivity to the relative OOP costs of medications or to the total burden of OOP costs. There is a need to rethink and recalculate the optimal prescription drug cost-sharing structures for patients with T2D to improve the medication adherence.

\section{ACKNOWLEDGEMENTS}

The authors would like to thank Dr. Douglas E. Faries and Dr. Joseph A. Johnston (Eli Lilly and Company) for their statistical and medical review of the manuscript. This study is funded by Eli Lilly and Company.

Funding. This preparation of this manuscript and the journals Rapid Service Fee was funded by Eli Lilly and Company.

Authorship. All named authors meet the International Committee of Medical Journal Editors (ICMJE) criteria for authorship for this article, take responsibility for the integrity of the work as a whole, and have given their approval for this version to be published.

Author Contributions. David Nelson has contributed to the conception, design, acquisition, analysis, and interpretation of the work, and writing of the manuscript. Pamela Heaton and Ana Hincapie have contributed towards the interpretation of the data for the work. Jieling Chen has contributed to the study conception, design, interpretation of the work, and writing of the manuscript. Shirin Ghodke has contributed towards the interpretation of the data for work and writing of the manuscript. All authors have contributed towards the critical revision of the manuscript.

Disclosures. David R. Nelson is an employee and stockholder of Eli Lilly and Company. Pamela Heaton and Ana Hincapie report research grants from Eli Lilly and Company. Shirin Ghodke is an employee of Eli Lilly Services India Pvt. Ltd and a minor stockholder of Eli Lilly and Company. Jieling Chen was an employee of Eli Lilly and Company and has no other relevant conflicts of interest to declare. The authors have no other conflict of interests relevant to this study.

Compliance with Ethics Guidelines. MEPS is a publicly available de-identified data source. MEPS has been reviewed and approved by the Westat IRB, established under a multi-project assurance (MPA M-1531) granted by the Office 
for Protection from Research Risks (OPRR). The project is reviewed and the approval renewed annually.

Data Availability. Data from the MEPS are freely available from https://meps.ahrq.gov/ data_stats/download_data_files.jsp. Codes used for data analysis are available on request from the corresponding author.

Open Access. This article is licensed under a Creative Commons Attribution-NonCommercial 4.0 International License, which permits any non-commercial use, sharing, adaptation, distribution and reproduction in any medium or format, as long as you give appropriate credit to the original author(s) and the source, provide a link to the Creative Commons licence, and indicate if changes were made. The images or other third party material in this article are included in the article's Creative Commons licence, unless indicated otherwise in a credit line to the material. If material is not included in the article's Creative Commons licence and your intended use is not permitted by statutory regulation or exceeds the permitted use, you will need to obtain permission directly from the copyright holder. To view a copy of this licence, visit http:// creativecommons.org/licenses/by-nc/4.0/.

\section{REFERENCES}

1. Feldman R, Dowd B. A new estimate of the welfare loss of excess health insurance. Am Econ Rev. 1991;81(1):287-301.

2. Feldstein MS. The welfare loss of excess health insurance. J Polit Econ. 1973;81(2):251-80.

3. Keeler EB, Rolph JE. How cost sharing reduced medical spending of participants in the health insurance experiment. JAMA. 1983;249(16):2220-2.

4. Centers for Medicare \& Medicaid Services. NHE Fact Sheet, 2017 Baltimore. 2017. http://www.cms.gov/ Research-Statistics-Data-and-Systems/StatisticsTrends-and-Reports/NationalHealthExpendData/ NHE-Fact-Sheet.html. Accessed 1 Jan 2021.
5. Claxton G, Rae M, Long M, Damico A. Employer health benefits: 2018 annual survey. San Francisco: The Kaiser Family Foundation.

6. Manning WG, Marquis MS. Health insurance: the tradeoff between risk pooling and moral hazard. J Health Econ. 1996;15(5):609-39.

7. Pauly MV. The economics of moral hazard: comment. Am Econ Rev. 1968;58(3):531-7.

8. Nyman JA. Is "moral hazard" inefficient? The policy implications of a new theory. Health Aff (Millwood). 2004;23(5):194-9.

9. Rice T. An alternative framework for evaluating welfare losses in the health care market. J Health Econ. 1992;11(1):86-92.

10. Goldman AL, Woolhandler S, Himmelstein DU, Bor $\mathrm{DH}$, McCormick D. Out-of-pocket spending and premium contributions after implementation of the affordable care act. JAMA Intern Med. 2018;178(3):347-55.

11. Sinnott SJ, Buckley C, O'Riordan D, Bradley C, Whelton $\mathrm{H}$. The effect of copayments for prescriptions on adherence to prescription medicines in publicly insured populations; a systematic review and meta-analysis. PLoS ONE. 2013;8(5):e64914.

12. Eaddy MT, Cook CL, O’Day K, Burch SP, Cantrell CR. How patient cost-sharing trends affect adherence and outcomes: a literature review. $\mathrm{P} \& \mathrm{~T}$. 2012;37(1):45-55.

13. Mann BS, Barnieh L, Tang $\mathrm{K}$, et al. Association between drug insurance cost sharing strategies and outcomes in patients with chronic diseases: a systematic review. PLoS ONE. 2014;9(3):e89168.

14. Goldman DP, Joyce GF, Zheng Y. Prescription drug cost sharing: associations with medication and medical utilization and spending and health. JAMA. 2007;298(1):61-9.

15. American Diabetes Association. 9. Pharmacologic approaches to glycemic treatment: Standards of Medical Care in Diabetes-2020. Diabetes Care. 2020;43(Suppl 1):S98-S110.

16. Abdul-Ghani MA, Puckett C, Triplitt C, et al. Initial combination therapy with metformin, pioglitazone and exenatide is more effective than sequential add-on therapy in subjects with new-onset diabetes. Results from the Efficacy and Durability of Initial Combination Therapy for Type 2 Diabetes (EDICT): a randomized trial. Diabetes Obes Metab. 2015;17(3):268-75.

17. Phung OJ, Sobieraj DM, Engel SS, Rajpathak SN. Early combination therapy for the treatment of 
type 2 diabetes mellitus: systematic review and meta-analysis. Diabetes Obes Metab. 2014;16(5): 410-7.

18. Matthews DR, Paldánius PM, Proot P, Chiang Y, Stumvoll M, Del Prato S. Glycaemic durability of an early combination therapy with vildagliptin and metformin versus sequential metformin monotherapy in newly diagnosed type 2 diabetes (VERIFY): a 5-year, multicentre, randomised, double-blind trial. Lancet. 2019;394(10208):1519-29.

19. Polonsky WH, Henry RR. Poor medication adherence in type 2 diabetes: recognizing the scope of the problem and its key contributors. Patient Prefer Adherence. 2016;10:1299-307.

20. Balkrishnan R, Rajagopalan R, Camacho FT, Huston SA, Murray FT, Anderson RT. Predictors of medication adherence and associated health care costs in an older population with type 2 diabetes mellitus: a longitudinal cohort study. Clin Ther. 2003;25(11): 2958-71.

21. Shenolikar RA, Balkrishnan R, Camacho FT, Whitmire JT, Anderson RT. Comparison of medication adherence and associated health care costs after introduction of pioglitazone treatment in African Americans versus all other races in patients with type 2 diabetes mellitus: a retrospective data analysis. Clin Ther. 2006;28(8):1199-207.

22. Kirkman MS, Rowan-Martin MT, Levin R, et al. Determinants of adherence to diabetes medications: findings from a large pharmacy claims database. Diabetes Care. 2015;38(4):604-9.

23. Karter AJ, Parker MM, Solomon MD, et al. Effect of out-of-pocket cost on medication initiation, adherence, and persistence among patients with type 2 diabetes: the Diabetes Study of Northern California (DISTANCE). Health Serv Res. 2018;53(2):1227-47.

24. Brundisini F, Vanstone M, Hulan D, DeJean D, Giacomini M. Type 2 diabetes patients' and providers' differing perspectives on medication nonadherence: a qualitative meta-synthesis. BMC Health Serv Res. 2015;15(1):516.

25. Salas M, Hughes D, Zuluaga A, Vardeva K, Lebmeier $\mathrm{M}$. Costs of medication nonadherence in patients with diabetes mellitus: a systematic review and critical analysis of the literature. Value Health. 2009;12(6):915-22.

26. MEPS-HC Panel Design and Collection Process. Rockville: Agency for Healthcare Research and Quality; 2021. https://meps.ahrq.gov/mepsweb/ survey_comp/hc_data_collection.jsp. Accessed Jan $1,2021$.
27. Miller GE, Sarpong EM, Hill SC. Does increased adherence to medications change health care financial burdens for adults with diabetes? J Diabetes. $2015 ; 7(6): 872-80$.

28. Brown $\mathrm{MB}$, Forsythe $\mathrm{AB}$. Robust tests for the equality of variances. J Am Stat Assoc. 1974;69(346):364-7.

29. Zweifel P, Manning WG. Moral hazard and consumer incentives in health care. In: Culyer AJ, Newhouse JP, editors. Handbook of health economics, Vol 1. Amsterdam: Elsevier; 2000. p. 409-59.

30. Cutler DM, Zeckhauser RJ. The anatomy of health insurance. Culyer AJ, Newhouse JP, editors. In: Handbook of health economics, Vol 1. Amsterdam: Elsevier; 2000. p. 563-643.

31. Lohr KN, Brook RH, Kamberg CJ, et al. Effect of cost sharing on use of medically effective and less effective care. Med Care. 1986;24(Suppl 9):S31-8.

32. Giorgino F, Penfornis A, Pechtner V, Gentilella R, Corcos A. Adherence to antihyperglycemic medications and glucagon-like peptide 1-receptor agonists in type 2 diabetes: clinical consequences and strategies for improvement. Patient Prefer Adherence. 2018;12:707-19.

33. World Health Organization. Adherence to long-term therapies: evidence for action. 2003. https://www. who.int/chp/knowledge/publications/adherence_ report/en/. Accessed 1 Jan 2021.

34. Ross-Degnan D, Wallace J, Zhang F, Soumerai SB, Garabedian L, Wharam JF. Reduced cost-sharing for preventive drugs preferentially benefits low-income patients with diabetes in high deductible health plans with health savings accounts. Med Care. 2020;58(Suppl 6):S4-13.

35. Agarwal R, Gupta A, Fendrick AM. Value-based insurance design improves medication adherence without an increase in total health care spending. Health Aff (Millwood). 2018;37(7):1057-64.

36. Lee LF. Specification error in multinomial logit models: analysis of the omitted variable bias. J Econ. 1982;20(2):197-209.

37. Cinelli C, Hazlett C. Making sense of sensitivity: extending omitted variable bias. J R Stat Soc B. 2020;82:39-67.

38. Crown WH. Health care expenditure modeling with observational databases: how can economic theory help? ISPOR Connect. 2014;20(1):3-4. 